SECTION 6. Metallurgy and energy.

Ishkulova Aliya Rifovna

graduate student of department "Automation of technological processes and production"

Ufa state aviation technical university

\title{
ANALYSIS OF CONSTRUCTIVE FEATURES ANODE FOR PLATING
}

In the article analyzes the advantages and disadvantages of the basic types anodes used for plating.

Keywords: electroplating, flat plate, perforated plate, figured anode.

\section{УДК 621.357.7.035 (075)}

\section{АНАЛИЗ КОНСТРУКТИВНЫХ ОСОБЕННОСТЕЙ АНОДОВ ДЛЯ НАНЕСЕНИЯ ГАЛЬВАНИЧЕСКИХ ПОКРЫТИЙ}

В статье проведен анализ преимуществ и недостатком основных типов анодов применяемых для нанесения гальванических покрытий.

Ключевые слова: гальваническое покрытие, плоский анод, перфорированный анод, фигурный анод.

Аноды являются одним из основным конструктивным элементов гальванических ванн. В большинстве технологических процессах нанесения металлических покрытий электрохимическим способом аноды это наиболее сложная и требующая особого внимания часть. От устройства (конструкции и материалов) анодов в большей степени зависит равномерность покрытий, напряжение в ванне и расход металла и электроэнергии на осаждения металлических покрытий.

При разработке анодов необходимо соблюдать ряд условий и требований предъявляемых к ним в зависимости от технологического процесса, вида покрытия, свойств электролита и конфигурации деталей. Материал электрода должен быть недорогим, доступным, удобным в обработке, механические свойства которого позволяли бы придать электроду необходимые размеры и геометрические формы.

Электрохимические характеристики материала электрода должны соответствовать проводимому процессу. Необходимы достаточная селективность, чтобы получить высокий выход целевого продукта по току, возможно более низкое перенапряжение для процессов протекающих на электродах.

Должна быть высокая коррозионная стойкость материала, чтобы обеспечить длительный тур работы электролизера между ремонтами и 
исключить загрязнения электролита и конечных продуктов электролиза продуктами коррозии.

Электроды должны иметь такую конструкцию, которая обеспечивала бы достаточно развитую рабочую поверхность для интенсификации процесса и создания компактных электролизеров, рассчитанных на большие нагрузки. Кроме того, в конструкции электродов должна быть предусмотрена возможность максимального сближения работающих поверхностей анода и катода и соблюдения равенства межэлектродного расстояния (МЭР) по всей поверхности электродов с достаточной точностью.

В конструкции электродов необходимо предусмотреть и облегченный отвод газовых продуктов электродных реакций из зоны прохождения тока по электролиту, чтобы снизить потери напряжения на преодоление электрического сопротивления газонаполненного электролита

Желательно, чтобы электроды были просты в изготовлении. Всегда к электродам предъявляются требования взаимозаменяемости и удобства при хранении, транспортировке и монтаже электролизеров [4, с. 32].

Геометрические формы анодов, применяемых в технологических процессах нанесения гальванических покрытий, очень разнообразны. Формы анодов во многом зависят от технологического процесса, свойств электролита и конфигурации покрываемой детали.

В процессах нанесения гальванических покрытий получили применение различные варианты конструкции анодов: плоские, перфорированные, сетчатые, пластинчатые и фигурные.

Наиболее широкое применение получили

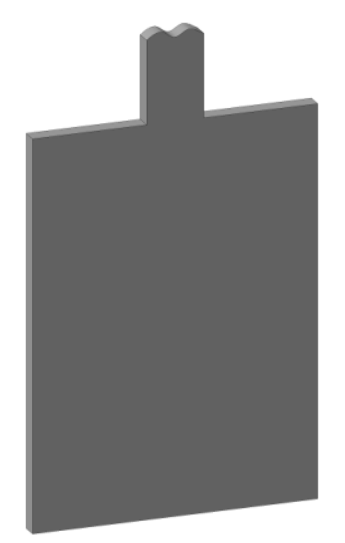

Рисунок 1 - Плоский металлический анод плоские металлические аноды (рисунок 1). Данная конструкция анодов преимущественно недороги и просты в изготовлении. При нанесении гальванических покрытий на детали сложной геометрической формы с применением плоских анодов выравнивание МЭР достигается за счет увеличения расстояния между анодом и катодом, в следствие чего возрастает омическое сопротивление и расход электроэнергии на осаждение требуемой толщины покрытия.

В процессах электрохимического нанесения гальванических покрытий, протекающих с выделение газа, получили развитие конструкции анодов, проницаемых для газов и жидкости, так как пузырьки газа уменьшают свободное сечение электролита, что приводит к увеличению омического сопротивления и потерь напряжения на преодоление сопротивления газонаполненного электролита. 
Для решения проблемы отвода газов были предложены конструкции электродов, проницаемых для газов и жидкостей. Разработка малоизнашивающихся анодов на титановой основе позволила сконструировать разнообразные типы анодов с развитой поверхностью (рисунок 2) из перфорированного листа или пластины, титановой проволоки или сетки с активным покрытием, а также в виде набора различных элементов, пластин, штырей или стержней.

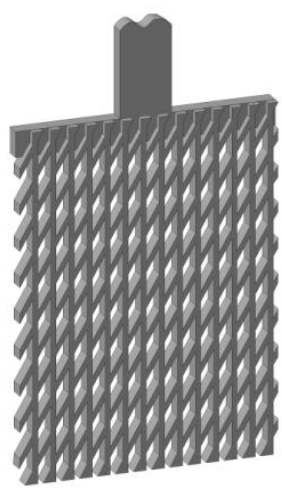

a

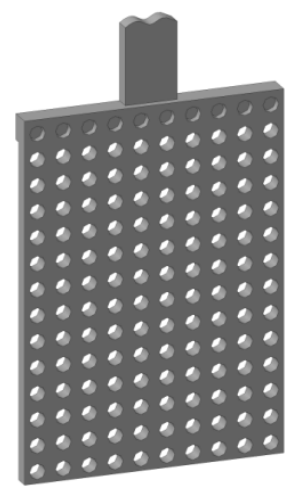

6

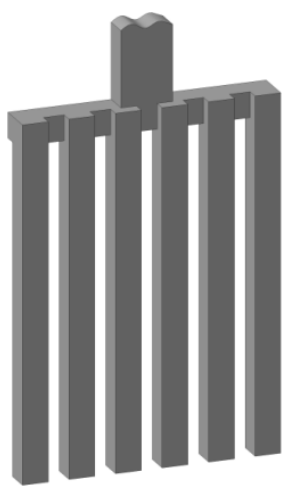

B

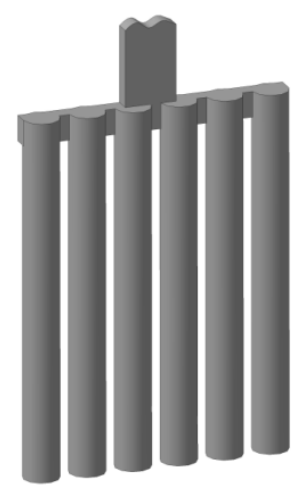

$\Gamma$

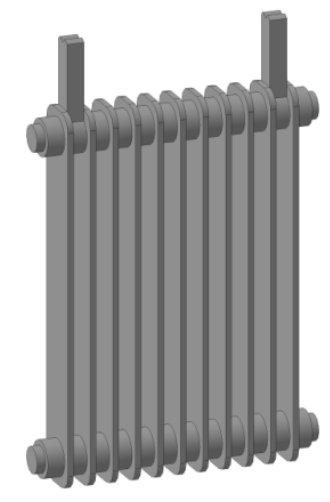

Д

Рисунок 2 - Варианты конструкций анодов, проницаемых для газов и жидкости:

a-сетчатый; б-перфорированный; в - из четырехугольных стрежней; г-из кругльх стержней;

Однако слишком частые прорези или отверстия в материале анода сильно ослабляют его механическую прочность и могут привести к разрушению и осыпанию анода в процессе работы. Перфорация изменяет рабочую поверхность анода, вследствие чего возникает неравномерность в распределении тока в электролите, что необходимо учитывать при определении оптимальной формы перфорации. Лобовая поверхность анода уменьшается из-за отверстий, однако при этом появляется дополнительная поверхность боковых стенок отверстий; в какой-то степени возможна работа также и тыльной стороны анодного листа.

Так же способствует облегчению отвода газов выполнение на лобовой поверхность анодов вертикальных пазов или выступов, как это показано на рисунке 3 . Помимо увеличения рабочей поверхности электрода при этом облегчаются отвод газа и циркуляция электролита через вертикальные каналы для
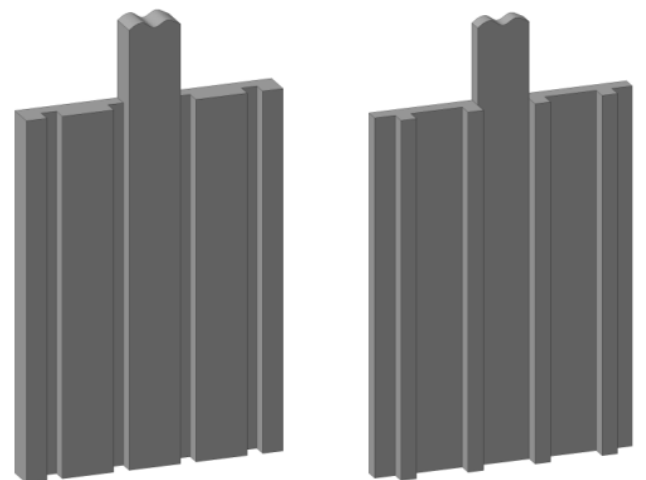

Рисунок 3 - Конструкции анодов с вертикальными пазами (а) и выступами (б) газожидкостной смеси. 
При изготовлении анодов проницаемых для газов и жидкости особые требования предъявляются к материалам для их изготовления. Материалы для данного типа анодов должны обладать механическими свойствами, позволяющими придавать электроду необходимые геометрические формы, а так же материал должен быть удобен в обработке и обладать износостойкостью, во избежание разрушения анодов. Таким образом, изготовление анодов проницаемых для газов и жидкости является сложным, трудоемким и дорогостоящим процессом.

Для повышения уровня равномерности покрытий на деталях сложной геометрической формы применяются фигурные аноды повторяющие геометрическую конфигурацию обрабатываемой детали. Применение фигурных анодов позволяет соблюдать равенство МЭР по всей поверхности электродов, что позволяет сократить расстояние между электродами, за счет чего уменьшается омическое сопротивление и потери электроэнергии на преодоление сопротивления электролита, но в тоже время данная конструкция анодов не обладают универсальность по сравнению с другими типа. К тому же, применение фигурных анодов зачастую требуется применять дополнительных приспособлений (защитных катодов и экранов), позволяющих отвести излишки тока от ребер и других наиболее активных частей поверхности деталей, установка которых требует особой точности и навыка.

Материалы для изготовления данных анодов должны быть легки в обработки, для придания им формы повторяющие конфигурацию обрабатываемой детали.

Исходя из выше сказанного, для обработки большой номенклатуры деталей необходимо изготавливать аноды для каждой детали, что является довольно затратным, но эти затраты оправдываются качество покрытия. Таким образом, в процессах нанесения гальванических покрытий применяется различные конструкции анодов. Выбор наиболее подходящей конструкции в основном зависит от свойств электролитов, протекания технологического процесса и геометрических форм обрабатываемых деталей.

\section{Литература}

1. Гамбург Ю. Д. Гальванические покрытия. Справочник по применению. - М.: Техника, 2006. - 216 с.

2. Лаворко П. К. Пособие мастеру цеха гальванических покрытий. - М.: Машиностроение, 1969. - $272 \mathrm{c}$.

3. Лобанов С. А. Практические советы гальванику. - Л.: Машиностроение, 1983.-248 с.

4. Якименко Л. М. Электродные материалы в прикладной электрохимии. - М.: «Химия», 1977. - 264 с. 